\section{OAK RIDGE $\mathrm{Y}-12$ PLANT}

LOCKHEED MATTIN

\section{USING A COORDINATE MEASURING MACHINE TO CALIBRATE STEP GAGES AT WORLD CLASS LEVELS OF UNCERTAINTY}

August 1996

DEC 201950

$$
\text { S. } 01
$$

Nick Zurcher

Oak Ridge Centers for Manufacturing Technology U.S. Department of Energy Facilities Oak Ridge, Tennessee

Prepared by the Oak Ridge Y-12 Plant Oak Ridge, Tennessee 37831-8091

Managed by



- Lockheed Martin Energy Systems, Inc. for the U.S. Department of Energy under contract DE-AC05-84OR21400 


\section{DISCLAIMER}

This report was prepared as an account of work sponsored by an agency of the United States Government. Neither the United States Government nor any agency thereof, nor any of their employees, makes any warranty, express or implied, or assumes any legal liability or responsibility for the accuracy, completeness, or usefulness of any information, apparatus, product, or process disclosed, or represents that its use would not infringe privately owned rights. Reference herein to any specific commercial product, process, or service by trade name, trademark, manufacturer, or otherwise, does not necessarily constitute or imply its endorsement, recommendation, or favoring by the United States Government or any agency thereof. The views and opinions of authors expressed herein do not necessarily state or reflect those of the United States Government or any agency thereof. 


\title{
USING A COORDINATE MEASURING MACHINE TO CALIBRATE STEP GAGES AT WORLD CLASS LEVELS OF UNCERTAINTY
}

\author{
August 1996 \\ Nick Zurcher \\ Oak Ridge Centers For Manufacturing Technology \\ U.S. Department of Energy Facilities \\ Oak Ridge, Tennessee \\ Prepared by \\ the Oak Ridge Y-12 Plant \\ Oak Ridge, Tennessee 37831-8091 \\ Managed by \\ Lockheed Martin Energy Systems, Inc. \\ for the \\ U.S. Department of Energy \\ under contract \\ DE-AC05-84OR21400
}

DISCLAIMER

This report was prepared as an account of work sponsored by an agency of the United States Government. Neither the United States Govemment nor any agency thereof, nor any of their employees, makes any warranty, express or implied, or assumes any legal liability or responsibility for the accuracy, completeness, or usefulness of any information, apparatus, product, or process disclosed, or represents that Its use would not infringe privately owned rights. Reference herein to any specific commercial product, process, or service by trade name, trademark, manufacturer, or otherwise, does not necessarily constitute or imply its endorsement, recommendation, or favoring by the United States Govemment or any agency thereof. The views and opinions of authors expressed herein do not necessarily state or reflect those of the United Slates Government or any agency thereol. 


\section{DISCLAIMIER}

Portions of this document may be illegible in electronic image products. Images are produced from the best available original document. 


\section{USING A COORDINATE MEASURING MACHINE TO CALIBRATE STEP GAGES AT WORLD CLASS LEVELS OF UNCERTAINTY}

\section{INTRODUCTION}

The purpose of this paper is to relate some of the experiences of using a coordinate measuring machine $(\mathrm{CMM})$ to calibrate long end standards and step gages at measurement uncertainties of less than $0.5 \mu \mathrm{m}$. It is not the intent of this paper to suggest that everyone should return to his or her laboratory and change the way CMMs are operated nor to suggest that the methods discussed here are even the best methods. The intent is to provide some food for thought, based on real experiences, about the use of a CMM to measure at low levels of uncertainty. As will become apparent, a lot of the issues discussed really apply to any dimensional measuring technique operating at low levels of uncertainty, not just a CMM.

The discussion in this paper is based on measuring one-dimensional end standards and step gages placed along the $x$-axis of the Moore M-60 CMM located at the Oak Ridge Metrology Center, which is part of the Oak Ridge Centers for Manufacturing Technology at the Y-12 Plant (formerly used in manufacturing nuclear weapons parts) in Oak Ridge, Tennessee. When the Cold War ended, the U.S. Department of Energy (DOE) pushed to make nuclear weapons technology available to U.S. industry. As part of this technology transfer effort, it was determined that the M-60 could be used by the National Institute of Standards and Technology (NIST) to provide a calibration service for step gages. Previously, U.S. industrialists had to go to Germany for step gage calibrations at the lowest levels of measurement uncertainty. Much of the discussion that follows is based on the process developed to use the M-60 for the NIST calibration.

Acknowledgment and thanks are given to Dr. Ted Doiron of NIST for help and guidance in developing and evaluating the M-60 measuring process. Special acknowledgment is also given to Glenn Atchley of Y-12, whose metrology skills and patience have been instrumental in the "world-class" performance of the M- 60 .

\section{THE M-60 COORDINATE MEASURING MACHINE}

As shown in Fig. 1, the Moore M-60 CMM is a fixed-bridge, moving-table design with roller bearings in double $\mathrm{V}$-ways on the $x$ - and $y$-axes and air bearings on the $z$-axis ram. The machine structure is cast iron, and the ram is stainless steel.

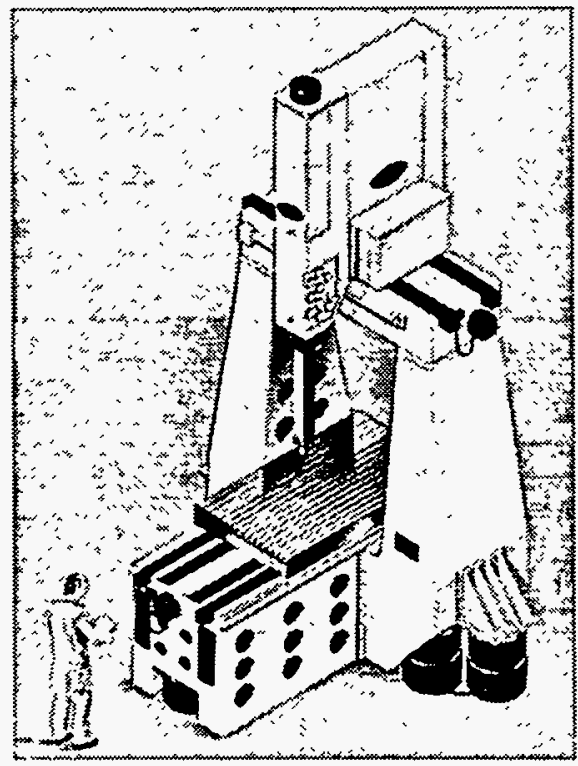

Fig. 1. Artist's rendering of the Moore M-60 CMM. 
The 55-ton, 7-m-tall machine rests on air isolation pads. It is equipped with a Tridim 3-D Gauge Head manufactured by Movomatic of Switzerland. The M-60 uses a single laser with beam splitting to provide $0.01-\mu \mathrm{m}$ resolution positioning of all three axes. The measuring volume is the following: $x=1397 \mathrm{~mm}, y=1219 \mathrm{~mm}$, and $z=1295 \mathrm{~mm}$. The 2-sigma uncertainty of the 1 -D calibration measurements is $\pm(0.3+0.4 L) \mu \mathrm{m}$, where $L=$ length in meters. For example, the uncertainty of a 1 -m-long gage block is $\pm 0.7 \mu \mathrm{m}$.

\section{TEMPERATURE}

Under the general topic of temperature there are three main areas of concern to discuss:

1. the temperature of the artifact,

2. effects of non-steady-state heat sources on the CMM and the artifact, and

3. calibration of temperature measuring systems.

\section{Temperature of the Artifact}

The largest single source of uncertainty in the entire measuring process for 1-D on the M-60 is knowing the temperature of the step gage. There is a law of nature that says that materials change size with changes in temperature. If you do not know the temperature, how can you know the size of the artifact? By established standards, measurements are either made at $20^{\circ} \mathrm{C}$ or else are adjusted using the coefficient of thermal expansion (CTE) for the particular material being measured. As a result, the uncertainty of knowing the real CTE becomes another source of error.

The fact of the matter is that a 1-m-long steel step gage will change length by $0.35 \mu \mathrm{m}$ for a $0.03^{\circ} \mathrm{C}$ change in temperature. Therefore, the measuring process would start with a $0.35 \mu \mathrm{m}$ error before the CMM has even started moving. For the M- 60 this would represent almost $50 \%$ of the entire process uncertainty at this length. No wonder so much concern is given to temperature control and measurement.

It is important to understand that the artifact temperature is not the same as the air temperature, so the artifact temperature itself must be measured. It does not take rocket science to understand that an artifact on the table of a CMM exchanges heat with its surroundings, not only by convection with the air but also by conduction with whatever it touches and by radiation with other nearby heat sources. The problem is that oftentimes we overlook the effect of these three heat-transfer mechanisms. Again, if the allowable uncertainty is $5.0 \mu \mathrm{m}$ rather than $0.5 \mu \mathrm{m}$, then the concern about temperature diminishes.

The desire for the M-60 was to have the artifact as close as possible to $20^{\circ} \mathrm{C}$ so as to minimize the effect of CTE uncertainty. Therefore, the set point for the room air temperature was initially set at $20^{\circ} \mathrm{C}$-that is, until the temperature of an artifact on the CMM table was measured and found to be above $20^{\circ} \mathrm{C}$. This was the first wake-up call that things other than air temperature 
affect the artifact temperature. We began to realize that heat was being transferred from the lights, computers, and the machine itself to the artifact and that the only thing that could be changed was the air temperature. As a result, the set point for the M-60 room air temperature has been changed to $19.911^{\circ} \mathrm{C}$ to bring the artifacts on the $\mathrm{CMM}$ closer to $20^{\circ} \mathrm{C}$.

A similar educational experience took place when we noticed that two similar artifacts placed side by side on the table of the $\mathrm{CMM}$ had a temperature difference of about $0.04^{\circ} \mathrm{C}$ ! The temperature of a rectangular gage block mounted on two roll pins was $19.974^{\circ} \mathrm{C}$, while a rectangularly shaped solid-piece step gage that was lying on its side next to the gage block had a temperature of $20.017^{\circ} \mathrm{C}$. At first it was thought that the temperature measuring system had failed, so the thermistors used to measure the artifact temperatures were swapped between the two artifacts. The results did not change. Then we noticed that the block on the pins had almost no contact with the CMM and was the cooler of the two, while the other block had a large surface of contact with the CMM and was warmer. The big difference in surface area in contact with the CMM meant a significant difference in heat transfer by conduction from the CMM table. The bottom line is that you have to measure the temperature of the artifact when you measure the size of the artifact.

An example of the CMM temperature changing without changing the air temperature took place when the three room lights were turned off. After soaking overnight, the temperature of the table had dropped about $0.017^{\circ} \mathrm{C}$ but returned to normal the day after turning the lights on again. Even with infrared filters and special air vents, the lights were transferring heat by radiation to the CMM and whatever was on it. Hiccups in table temperature when new light bulbs have been installed raise the question of the heating effect of aging light bulbs.

\section{Effects of Non-Steady-State Heat Sources}

Varying heat sources will, by convection, conduction, and radiation, change the temperature of the artifact and the CMM, which will in turn change the size and shape of the artifact and CMM. As I have already noted, the correct length measurements cannot be made unless the artifact temperature is also measured. If the temperature is continually varying, then measuring the temperature that the artifact actually "feels" and reacts to becomes more and more uncertain. In other words, steady-state heat sources become a necessity so that the artifact "soaks" to a steady temperature that can be more easily measured.

The CMM itself will also react to varying heat sources, and this will result in varying machine geometry errors. Since the M-60 has all 21 parametric errors (roll, pitch, yaw, etc.) measured and stored in a static map, it is imperative that the machine make measurements at the same temperature at which it was mapped. It is known from temperature measurements throughout the machine castings that the temperature of the machine is far from uniform. For instance, one column of the machine is about $0.11^{\circ} \mathrm{C}$ warmer than the other because of the location of electronics in the room. But the same condition exists during mapping and artifact measuring-i.e., steady-state temperature conditions. 
Being inquisitive metrologists, we performed a test to determine if a change really occurred to the 10-ton cast iron column when the small amount of heat radiating from the electronics was changed. A 3-D body diagonal of the M-60 was measured using a laser metrology system. The 2108-mm length was measured, and a reflective barrier was installed to block the radiant energy from the electronics. After overnight soaking, the diagonal length had changed about $0.6 \mu \mathrm{m}$. The barrier was removed, and we allowed another night of soaking; this time, remeasurement showed that the $0.6 \mu \mathrm{m}$ had disappeared. The radiant energy of an operator entering the room can have a similar effect on the artifact and the CMM. Steady-state heat sources are a must at this level of measurement uncertainty.

The significant heat sources in the M-60 room are the air, the overhead lights, operator body heat, and electronics. (The mass of the machine seems to absorb any effect of the drive motors as a heat source.) Variation in heat sources is reduced by never turning off the lights or the electronics, keeping the operator out of the room, and having excellent air temperature control (discussed later).

One other variable that still exists and must be addressed is the back-and-forth movement of the table, which changes the "view" that the artifact has of the steady-state heat sources. For instance, when the table is moved back between the columns (machine home position), the table "sees" maximum shadowing by the bridge from the lights and by the column from the electronics, resulting in cooler table temperatures. Twenty-four-hour tests were performed measuring long gage blocks to look for changes of the block temperatures over time. It was noted that if the table was parked overnight between the columns before beginning the test, the temperature of the block would rise for $3 \mathrm{~h}$ and then remain virtually constant for the next $21 \mathrm{~h}$. As a result, the M-60 table is now parked in a position so the block temperature will already be at the "constant running" temperature, and the process can proceed without the 3-h warm-up time.

Approximately $6 \mathrm{~h}$ is required to perform six measurements of a 1-m-long step gage, and the average temperature of the gage will remain constant within $0.004^{\circ} \mathrm{C}$. However, uniformity of temperature along the length of the step gage is another concern. No conclusion has been reached on how to evaluate the effect of temperature gradients along the length of the gage, but the gradients surely add error to the measuring process. The step gage temperature is uniform within about $0.013^{\circ} \mathrm{C}$, and for now, a value for the effect has been estimated and included in the calculation of the overall measuring process uncertainty.

During these and other tests, it was also noted that approximately $10 \mathrm{~h}$ was required for the step gage to cool down to the "constant running" temperature after the operator left the room. As a result, the M-60 process requires that the artifacts and the CMM have a minimum soak time of $12 \mathrm{~h}$ with no one in the room before the measuring process can be started. The temperature probe application, artifact fixturing, software programming and debugging, and manual probing for artifact alignment must be finished before the 12-h soak. After the soak, the operator enters the room long enough to push the start button and then leaves the room for the duration of the run, which in some cases can take $12 \mathrm{~h}$. 
As already noted, good control of the air temperature is absolutely necessary to maintain steadystate conditions in the CMM room. The M-60 is located in an environmentally controlled laboratory facility that is approximately $7 \mathrm{~m}$ wide, $8 \mathrm{~m}$ high, and $10 \mathrm{~m}$ long. Airflow in the lab is horizontal laminar flow, with the $6.5 \mathrm{~m} \times 6.5 \mathrm{~m}$ inlet and outlet grills being located on opposite ends of the room. Air velocity is approximately $22 \mathrm{~m} / \mathrm{min}$. The air temperature is measured at 20 locations in front of the inlet grill to monitor the performance of the room air temperature controller and to evaluate the stratification of temperature entering the room. The 3-sigma statistical control limits for the average air temperature entering the room are $\pm 0.005^{\circ} \mathrm{C}$, and the maximum stratification of the air temperature is $0.05^{\circ} \mathrm{C}$. This may well be the best temperaturecontrolled laboratory in the world for a measuring machine of this size.

While the reliability of the room environmental control has been very high, there have been failures, generally caused by electrical power outages. It is interesting to note what happens to the air temperature and artifact temperature when a failure does happen. Shown in Fig. 2 is a plot of the air temperature and average temperature of a solid-type step gage lying on a flat fixture on the M-60 table when the room fans stopped operating. The data points, taken every $15 \mathrm{~min}$, show the different temperature reactions of the gage and the air to the stopping and starting of the air flow. The data points on the right portion of the graph were taken at 4-h intervals. The temperature of the gage did not return to normal until approximately $84 \mathrm{~h}$ after the air flow restarted. Twelve hours after the air flow restarted, length measurements of the step gage were made and corrected for the temperature that was measured, but the results were more than $1.0 \mu \mathrm{m}$ in error. Forty hours later another measurement was attempted, and the repeatability values were still not normal. This is further indication that it is difficult to measure while the temperature is changing.

\section{Calibration of Temperature Measuring Systems}

The need for knowing artifact temperatures to very low levels of uncertainty requires calibration of temperature measuring systems to very low levels of uncertainty. Calibration of temperaturemeasuring systems to this low uncertainty level has been a project unto itself. The M-60 temperature-measuring systems consist of thermistors (air probes and surface mount) and electronics to read the resistance and convert it to a temperature. Initially, the thermistors were removed from the electronics and sent to the temperature lab for calibration. When the system was reassembled, all the thermistors were attached to a copper block to test that they all at least read the same. The results were that individual thermistor readings varied widely. The next step was to procure a temperature-controlled bath and a standard platinum resistance thermometer (SPRT) and associated electronics to allow the thermistors and all their associated electronics to be calibrated as a complete system without any disassembly. The latest revision has been the addition of a triple-point-of-water cell to monitor the performance of the NIST-calibrated SPRT. Now during tests in the bath, all thermistors read the same within $0.001^{\circ} \mathrm{C}$, and the 2-sigma uncertainty is estimated to be better than $0.015^{\circ} \mathrm{C}$. 


\section{AIR TEMPERATURE FAILURE}



Fig. 2. Plot of gage temperature response to air temperature change.

\section{PROBE TIP CALIBRATION}

During measurement of a single-sided step gage, all the probings are in the same direction, so it is not necessary to know the probe tip size accurately. It is also not necessary to know the probe tip size accurately when measuring to determine the center location of a sphere, as on a ball bar. However, during probes of double-sided artifacts such as gage blocks or double-sided step gages, the uncertainty of the probe tip diameter becomes part of the measuring process. The M-60 normally calibrates the probe tip by calculating an effective probe tip diameter through measurement of a sphere of known size. For the 1-D measuring process, the normal calibration sphere has been replaced by a 1-in. gage block aligned parallel to the unknown artifact to be measured. This eliminates the uncertainty of the roundness of the probe tip and the roundness of the calibration sphere and also provides a better-known standard, since the NIST uncertainty of a gage block is lower than that of a 1 -in. sphere. This technique also "calibrates out" any deformation of the artifact surface when probed with a spherical tip, assuming the artifact material is similar to the 1-in. gage block material. This error is probably insignificant, particularly with only 6-7 $\mathrm{g}$ of probing force on the M-60. 
For the M-60, a numerical control (NC) program has been created to measure the 1-in. gage block and calculate the deviation from the known size of the block. If the deviation exceeds $0.05 \mu \mathrm{m}$, the program will edit the effective probe tip size and then remeasure the 1 -in. block. This cycle will continue until the deviation is within the $0.05-\mu \mathrm{m}$ tolerance. Once the operator makes a few manual probes for an initial alignment on the 1-in. gage block, the computer takes over and completes probe-tip calibration. This minimizes the involvement of the operator, and the heat from his body, in the process. The M-60 measuring process is so stable that, over weeks of measuring the 1-in. gage block, no change has been made to the effective probe tip size. As a result, consideration has been given to reducing the tolerance on measuring the 1-in. gage block from 0.05 to $0.025 \mu \mathrm{m}$.

\section{LENGTH MEASURING REPEATABILITY}

Another source of uncertainty in the measuring process is the nonrepeatability of length measurements. This includes nonrepeatability in both the probe head and the machine positioning. In an effort to reduce the effect of nonrepeatability, six length measurements of an artifact are made and averaged to produce the final result. The standard deviation of the six measurements is also calculated and monitored in an effort to identify questionable measurement results. On an average day the standard deviation of six length measurements will be about $0.10-0.15 \mu \mathrm{m}$ and on a good day will decrease to $0.05 \mu \mathrm{m}$ even on 1-m-long step gages. Table 1 shows the results of tests used to determine the repeatability capability of the M-60 along the $x$-axis. Various-length, high-quality length standards were measured multiple times, and the one standard deviation repeatability was compared to similar length steps on a long step gage, which was also measured multiple times. It has been noticed that changes in the weather during the measuring process appear to degrade the repeatability of the process. The automatic laser compensation system seems to have trouble keeping up with rapid changes in barometric pressure when a weather front moves through the area.
Table 1. Results of length-measuring repeatability tests on gage blocks and comparable lengths on a step gage

\begin{tabular}{lcc}
\hline Length & $\begin{array}{c}\text { Gage blocks }^{a} \\
\text { (16 runs) }\end{array}$ & $\begin{array}{c}\text { Step gage }^{a} \\
(30 \text { runs })\end{array}$ \\
\hline 1 in. $(20 \mathrm{~mm})$ & 0.08 & 0.10 \\
2 in. $(60 \mathrm{~mm})$ & 0.09 & 0.10 \\
10 in. $(260 \mathrm{~mm})$ & 0.08 & 0.11 \\
20 in. $(500 \mathrm{~mm})$ & 0.09 & 0.14 \\
24 in. $(600 \mathrm{~mm})$ & 0.11 & 0.14 \\
$800 \mathrm{~mm}$ & 0.10 & 0.13 \\
$1000 \mathrm{~mm}$ & 0.11 & 0.13 \\
42 -in. Zerodur & 0.11 & 0.14 \\
\hline
\end{tabular}

${ }^{a}$ One standard deviation in microns. 


\section{ARTIFACT QUALITY, MOUNTING, AND CLEANLINESS}

One of the more difficult sources of uncertainty to quantify is the effect of the quality of the artifact on the measuring process. The surface finish of datums and gaging surfaces as well as flatness and parallelism of these surfaces must be considered. The poorer the quality of the artifact, the more critical it becomes that the user measure exactly the same points on the artifact as were measured during its calibration. Considerable time is spent visually inspecting measuring surfaces; those artifacts showing questionable quality will be handled on a case-by-case basis. This may mean extra testing to determine the effect of the poor quality surfaces and/or changing the uncertainty value for the calibration.

Some length standards, by virtue of their design, are more susceptible than others to changing length when the method of holding them is changed. Some artifacts are mounted on pins at the Airy points while others are held at the Bessel points, and yet others are required to be held very flat. The calibration report must describe how the artifact was positioned during the calibration measurement, and the user must evaluate the effect if he/she wants to position it differently. The calibration data may not be valid if the artifact is held differently.

In the measurement of an artifact, it is important to ensure that it is the artifact that is being measured and not dirt on the surface of the artifact. This is a serious concern when the artifact is of an unknown size and there is thus no easy way to notice when dirt is being measured instead of the real surface of the artifact. The measuring surfaces must be clean! Considerable effort is put into cleaning and visually inspecting artifacts before mounting them on the CMM. Sometimes the effect of dirt can be seen in larger standard deviation values from the six measurements made. If the artifact has a known nominal size, then it is much easier to locate "strange" data. If the data indicate excess stock on the artifact, the first suspect is dirt.

\section{USE OF CHECK STANDARDS}

To operate a measuring process at submicron levels of uncertainty requires some method for continuously monitoring the performance of the process. This is generally done by measuring artifacts similar to the unknown artifact every time that an unknown is measured. After these similar artifacts—called check standards—are measured a sufficient number of times, one can calculate statistical control limits that will define when the measuring process is operating normally. Whenever an unknown artifact is measured on the $M-60$, at least three check standards are also measured. The result must be within their respective control limits before the result of the unknown will be accepted.

To monitor particular error sources in the measuring process on the M-60, we use check standards made of different materials. Two 1-m-long check standards are used, one made of steel and one made of Zerodur, which has a CTE of approximately zero. Since the Zerodur check standard does not change length as a consequence of temperature changes, it is not necessary to 
put temperature probes on this check standard. When the Zerodur check standard measures within its control limits, the M-60 is then believed to be operating normally. If the steel check standard, which must have its temperature measured, is outside of its control limits, the first thought is that there is a temperature measuring problem of some kind. A 1-m steel gage block makes a very good thermometer when the rest of the measuring process is operating properly. If both the steel and Zerodur check standards show the same error, then the first thought is that the M-60 measuring scale (i.e., the laser) has a problem - more than likely a laser compensation problem. Figure 3 shows the setup of the step gages, check standards, and calibration block on the M- 60 .

The control charts in Fig. 4 show some of the history of the 1-m steel check standard. As can be seen, the measuring process does not always behave as it should, and close attention to detail is necessary to correct problems as they occur. The present 3-sigma control limits for the steel check standard are $\pm 0.24 \mu \mathrm{m}$ and

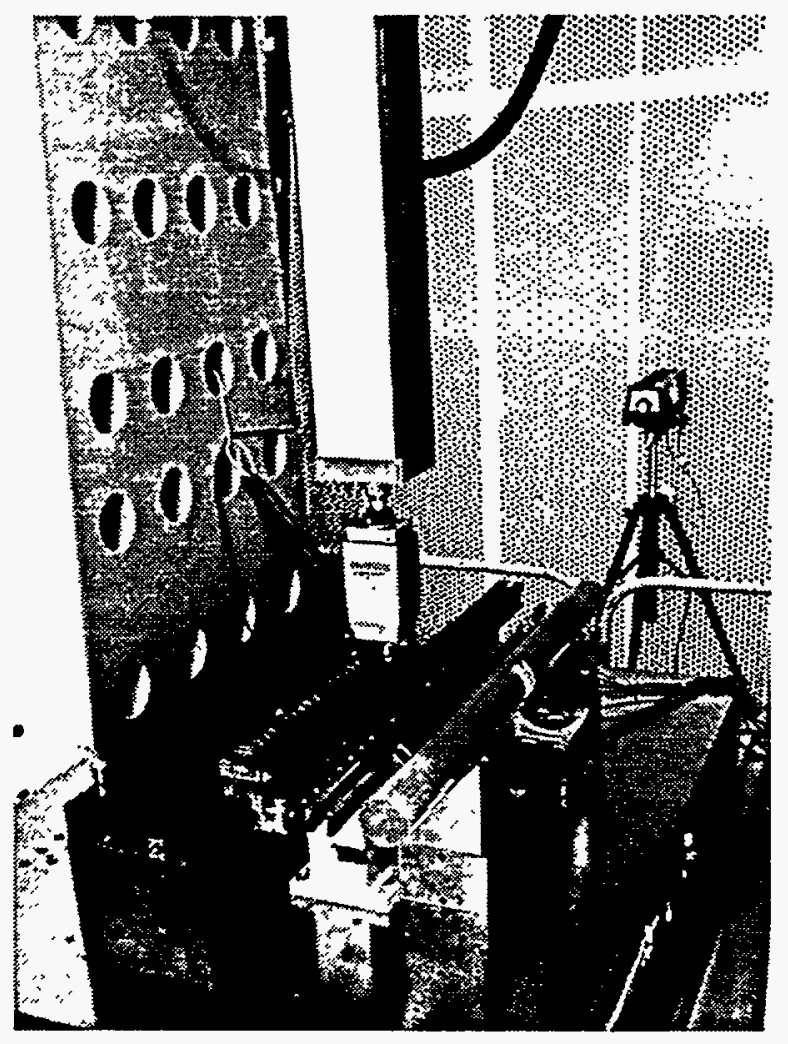

Fig. 3. Setup of step gages, Zerodur and steel check standards, and the 1-in. calibration block on the M-60 CMM.

for the Zerodur check standard are $\pm 0.21 \mu \mathrm{m}$; as these values indicate, the variation caused by the temperature measuring system is quite small.

\section{INTERCOMPARISONS}

It is great to have check standard control charts with very small control limits, since this indicates that the measuring process is very repeatable. However, the uncertainty of the overall process may still be large if the results being closely repeated are the wrong results. Periodically, a measurement test should be made on an artifact that has been measured by another competent laboratory with a similar measurement capability. Accreditation by the National Voluntary Laboratory Accreditation Program (NVLAP) requires that this type of intercomparison be done. This intercomparison will provide additional confidence that the measuring process is indeed operating properly within the stated uncertainty. Listed in Table 2 are results of the first intercomparison made on the M-60 using gage blocks and length standards calibrated by NIST. In September 1994 another intercomparison was made between the line scale interferometer at NIST and the M-60 using a 900-mm gage block. The results agreed within $30 \mathrm{~nm}$. 
M-60 CHECK STANDARD CONTROL CHART



\section{M-60 CHECK STANDARD CONTROL CHART}





Fig. 4. Three control charts for a 1000-mm check standard showing shifts resulting from changes in the measuring process. 
Table 2. Intercomparison of M-60 measurements and NIST-calibrated standards

\begin{tabular}{lcccccc}
\hline \multicolumn{1}{c}{ Standard } & Nominal & Day 1 & Day 2 & Day 3 & Day 4 & U $^{a}$ \\
\hline 1 in. & 0.999999 & 0 & -1 & -1 & -1 & 12 \\
2 in. & 1.999998 & -6 & -4 & -4 & -4 & 12 \\
10 in. & 10.000020 & -2 & -1 & 0 & 0 & 16 \\
20 in. (1536) & 20.000032 & +5 & +4 & +4 & +4 & 20 \\
24 -in. Zerodur & 24.027576 & -11 & -8 & -14 & -8 & 21 \\
800 mm & 31.496076 & -8 & -9 & -12 & -7 & 24 \\
$1000 \mathrm{~mm}$ & 39.370086 & -10 & -13 & -13 & -12 & 27 \\
\hline
\end{tabular}

Note: All deviations are in microinches.

${ }^{a} \mathrm{U}=$ Uncertainty calculated using $\pm(12+0.4 L) \mu \mathrm{in}$.

Shown in Figs. 5-8 are comparisons of measurements made on step gages by the PhysikalischTechnische Bundesanstalt (PTB, the primary German government calibration laboratory), by a DKD laboratory accredited by PTB, and by the M-60. One of the comparisons is the same step gage on the M-60 at two different times almost a year apart. The step gages are of a multipiece construction where solid thickness lugs are assembled together to create step gages of various lengths. This construction could allow lugs to move, as is indicated in one of the graphs.

\section{INTERCOMPARISON OF STEP GAGE CALIBRATION}



Fig. 5. Comparison of measurements made on one step gage at three different times. Two measurements were made at PTB and one on the M-60. Note that the apparent difference between the two PTB measurements is still within limits based on the stated uncertainties of each measurement. 


\section{INTERCOMPARISON OF STEP GAGE CALIBRATION}

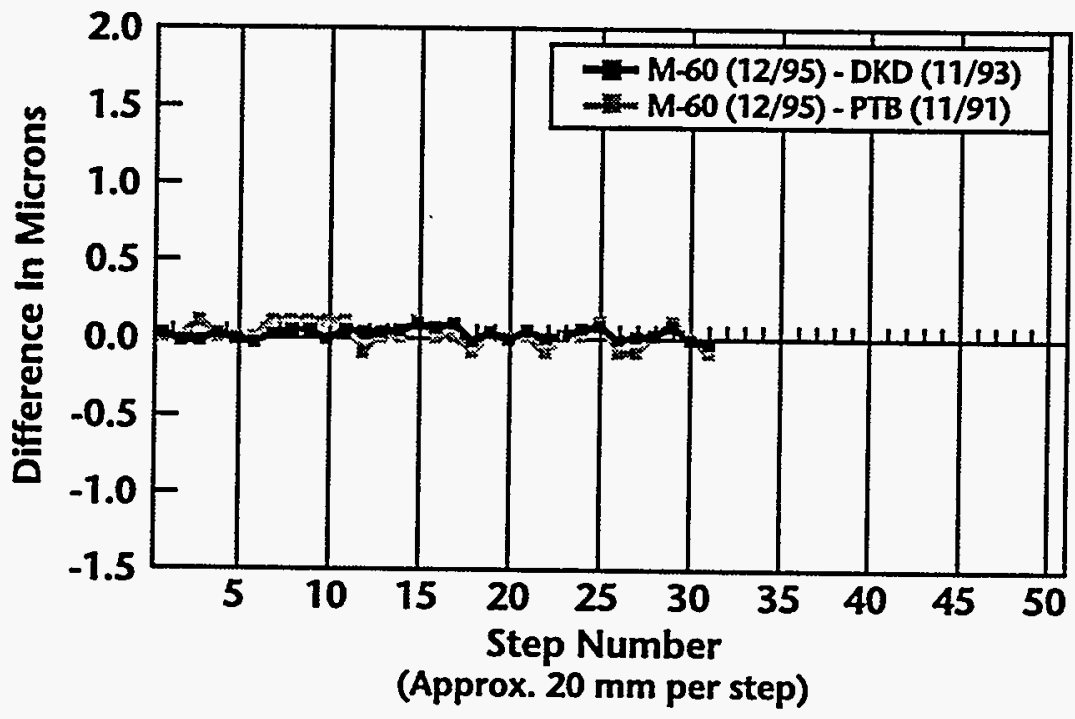

Fig. 6. Comparison of measurements made on one step gage at three different times, one at a DKDaccredited laboratory, one at PTB, and one on the M-60.



Fig. 7. Comparison of two measurements made on the M-60 on a 1-m-long step gage. 


\section{INTERCOMPARISON OF STEP GAGE CALIBRATION}

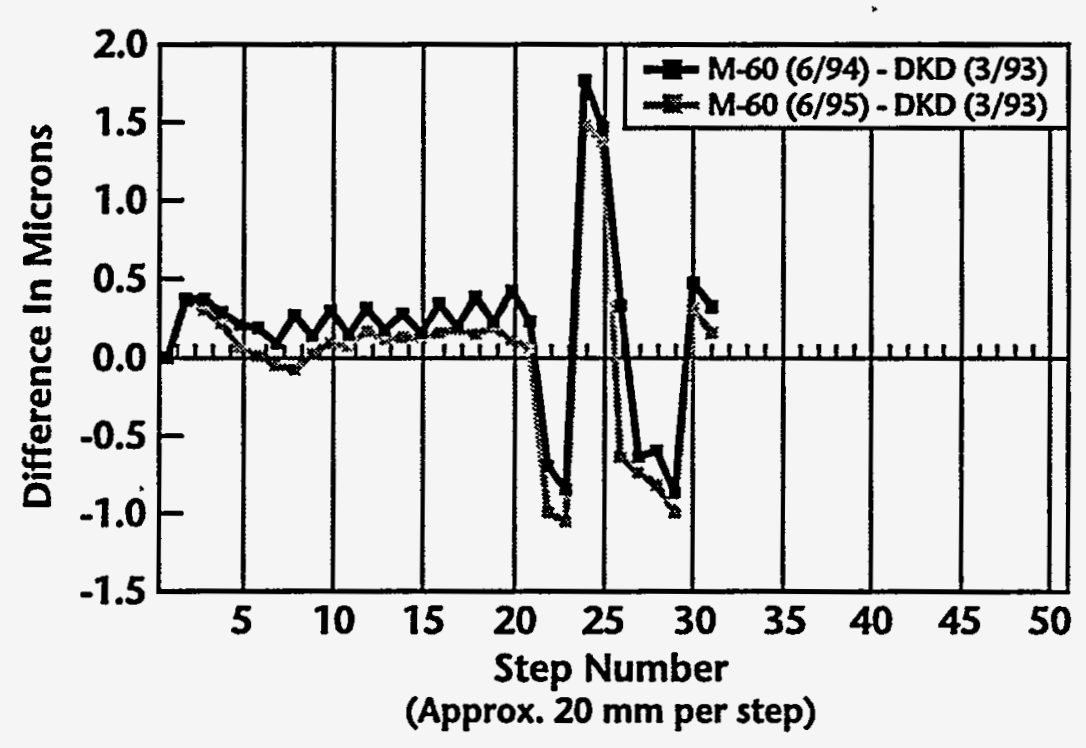

Fig. 8. Comparison of measurements made on one step gage at three different times, one at a DKDaccredited laboratory and two on the M-60. Data show an apparent movement of some steps between March 1993 and June 1994 but not between June 1994 and June 1995.

\section{PRECAUTIONS FOR THE USE OF STEP GAGES}

The following comments are offered to the user of step gages in regard to measuring uncertainties in the $0.5-\mu \mathrm{m}$ range, although these comments apply in any high-precision measurement:

- Cleanliness-Cleanliness is next to godliness! It is required so as to measure the step gage surface itself, not the dirt or oil film on the surface.

- Mounting-The user must evaluate the effect of mounting the gage differehtly than it was mounted during its calibration. This means that the user must understand how it was mounted during calibration.

- Temperature-The ability to measure temperature accurately can be the limiting factor in the ability to measure length accurately. 
- Shipping and storage-Any high-precision artifact is susceptible to handling damage, and this is particularly true for long skinny artifacts. It has been a shock to see the flimsy containers used to ship gages for calibration.

- Recalibration-The user must evaluate the risk of mission failure (i.e., the probability as well as the consequences of the gage changing) in determining what calibration interval to establish for the gage. Intervals ranging from 6 months to 2 years are common. 